\title{
Senescence-associated $\beta$-galactosidase in subcutaneous adipose tissue associates with altered glycaemic status and truncal fat in severe obesity
}

\author{
Christine Rouault $^{1} \cdot$ Geneviève Marcelin $^{1} \cdot$ Solia Adriouch ${ }^{1} \cdot$ Cindy Rose $^{1} \cdot$ Laurent Genser $^{1,2}$ - Marc Ambrosini ${ }^{1}$. \\ Jean-Christophe Bichet ${ }^{3}$ - Yanyan Zhang ${ }^{4}$. Florian Marquet ${ }^{1}$ - Judith Aron-Wisnewsky ${ }^{1,5}$. Christine Poitou ${ }^{1,5}$. \\ Sébastien André ${ }^{1} \cdot$ Geneviève Dérumeaux $^{4,6}$. Michèle Guerre-Millo ${ }^{1} \cdot$ Karine Clément ${ }^{1,5}$
}

Received: 6 March 2020 / Accepted: 1 September 2020 / Published online: 30 October 2020

(C) Springer-Verlag GmbH Germany, part of Springer Nature 2020

\begin{abstract}
Aim/hypothesis Altered adipose tissue secretory profile contributes to insulin resistance and type 2 diabetes in obesity. Preclinical studies have identified senescent cells as a cellular source of proinflammatory factors in adipose tissue of obese mice. In humans, potential links with obesity comorbidities are poorly defined. Here, we investigated adipose tissue senescent status and relationships with metabolic complications in human obesity.

Methods The study includes a prospective cohort of 227 individuals with severe obesity. A photometric method was used to quantify senescence-associated $\beta$-galactosidase (SA- $\beta$-gal) activity in paired subcutaneous and omental adipose tissue biopsies obtained during gastric surgery. Gene and secretory profiling was performed in adipose tissue biopsies and in human primary preadipocytes in the presence or absence of senolytic drugs targeting senescent cells. Participants were phenotyped for anthropometric and bioclinical variables, metabolic complications and gastric surgery-induced improvement to address relationships with adipose tissue SA- $\beta$-gal.

Results SA- $\beta$-gal activity was sevenfold higher in subcutaneous than in omental adipose tissue and not associated with BMI or chronological age. Several factors, including insulin-like growth factor binding protein 3 (IGFBP3), plasminogen activator inhibitor 1 (PAI1), C-C motif chemokine ligand 2 (CCL2) and IL-6, were upregulated in subcutaneous adipose tissue in relation with SA- $\beta$-gal ( $p$ for linear trend across tertiles $<0.05$ ) and in pre-adipocytes cultured with inflammatory macrophage conditioned media. Senolytic treatment reduced SA- $\beta$-gal staining and normalised these alterations. In the whole population, subcutaneous adipose tissue SA- $\beta$-gal activity was positively associated with serum leptin, markers of insulin resistance and increased trunk fat mass. Metabolic complications, including type 2 diabetes and dyslipidaemia, were more prevalent in patients with high levels of SA- $\beta$-gal, but improved with bariatric surgery whatever the initial adipose tissue senescent status.

Conclusions/interpretation This study highlights a phenotype of senescence in adipose tissue of severely obese individuals, which characterises prominently subcutaneous fat depots. Subcutaneous adipose tissue senescence is significantly linked to altered glucose metabolism and body fat distribution. Elimination of senescent cells through senolytic treatment could alleviate metabolic complications in severely obese people.
\end{abstract}

Keywords Adipose tissue $\cdot$ Bariatric surgery $\cdot$ Insulin resistance $\cdot$ Obesity $\cdot$ Senescence

Electronic supplementary material The online version of this article (https://doi.org/10.1007/s00125-020-05307-0) contains peer-reviewed but unedited supplementary material, which is available to authorised users.

Karine Clément

karine.clement@inserm.fr

Extended author information available on the last page of the article

$\begin{array}{ll}\text { Abbreviations } & \\ \text { AU } & \text { Arbitrary units } \\ \text { CCL2 } & \text { C-C motif chemokine ligand 2 } \\ \text { FAT score } & \text { Fibrosis score of adipose tissue } \\ \text { HDL-C } & \text { HDL-cholesterol } \\ \text { IGFBP3 } & \text { Insulin-like growth factor binding protein 3 } \\ \text { LME } & \text { Linear mixed-effects } \\ \text { M1/M2-CM } & \text { Proinflammatory/anti-inflammatory } \\ & \text { conditioned media }\end{array}$

\section{Abbreviations}

AU

FAT score

HDL-C

IGFBP3

LME

$\mathrm{M} 1 / \mathrm{M} 2-\mathrm{CM}$
Arbitrary units

$\mathrm{C}-\mathrm{C}$ motif chemokine ligand 2

HDL-cholesterol

Insulin-like growth factor binding protein 3

conditioned media 


\section{Research in context}

\section{What is already known about this subject?}

- Adipose tissue produces factors promoting metabolic complications in obesity

- Some complications might derive from senescent cells via their inflammatory senescence-associated secretory phenotype

- In mice, senescent cell accumulation in adipose tissue is related to obesity-induced alteration of glycaemic status

What is the key question?

- What is the pathological relevance of adipose tissue senescence in human obesity?

What are the new findings?

- Senescence-associated $\beta$-galactosidase (SA- $\beta$-gal) activity is sevenfold higher in subcutaneous than in omental adipose tissue of participants with severe obesity

- Subcutaneous adipose tissue with high SA- $\beta$-gal displays altered gene and secretory profiles characterised by upregulation of senescence- and inflammation-related factors

- Subcutaneous adipose tissue senescence associates with insulin resistance markers and higher prevalence of metabolic diseases, but does not mitigate bariatric surgery-induced recovery

How might this impact on clinical practice in the foreseeable future?

- Senolytic treatments could be clinically relevant to improve metabolic fitness through elimination of senescent cells in adipose tissue of severely obese patients

omAT

PAI1

PBMC

SA- $\beta$-gal

SASP

ScAT

SVF

\section{Introduction}

White adipose tissue is one of the largest endocrine organs with a unique plasticity property to orchestrate nutritional adaptation. In response to over-nutrition, adipose tissue expands by increasing triacylglycerol storage in adipocytes and undergoes metabolic and cellular adaptive changes that protect from lipotoxicity. In obesity, adipose tissue remodelling turns into a pathological process with excessive fat mass deposition [1]. Enlarged adipose tissue contributes to obesitylinked complications through the production of inflammatory and insulin-desensitising factors that promote local and distant organ dysfunction [2]. The cellular sources of these deleterious molecules are thought to be multiple. Inflammatory macrophages were first identified as major culprits. In addition, a wealth of adipose-tissue-resident immune cells shift in number and phenotype towards a proinflammatory status, characterising obesity [3]. Within obese adipose tissue, immune cells engage in complex crosstalk through cell contact or paracrine pathways, to which non-immune and progenitor cells contribute, accounting for altered adipose tissue endocrine and metabolic functions [4-7].

Among the myriad of adipose-tissue-produced molecules, some are proposed as mediators of cellular senescence. Senescence is a physiological response to prevent the proliferation of defective cells [8]. However, when senescent cells accumulate, they impair proper tissue function largely through their senescence-associated secretory phenotype (SASP) [9-11]. Several senescence biomarkers have been proposed to detect senescent cells in tissues (review in [10]). The most widely used biomarker relies on elevated senescenceassociated $\beta$-galactosidase (SA- $\beta$-gal) activity, as originally proposed by Dimri et al [12] and later shown to reflect increased amounts of the lysosomal enzyme in senescent cells $[13,14]$. Other markers relate to cell cycle arrest, including p16 or TP53 and its target cyclin-dependent kinase (CDK) inhibitor p21 [10]. Notably, drugs termed senolytics have been identified based on their capacity to eliminate senescent cells by targeting pro-survival or SASP pathways (review in [15]). Among them, dasatinib and quercetin were shown to be effective in delaying age-related symptoms in mice [16] and are now being tested in clinical trials [17].

In a pioneer study, Minamino et al revealed enhanced SA- $\beta$-gal activity, higher amounts of TP53 and increased expression of p21 in adipose tissue of genetically and dietinduced obese mice [18]. Genetic or senolytic-mediated depletion of senescent cells reduced inflammation and 
improved glycaemic status, supporting a causal role of adipose tissue senescence in obesity-induced metabolic complications in mouse models $[18,19]$. In humans, studies exploring adipose tissue senescence status remain scarce, despite increasing interest on senescence in metabolic diseases. Recently, Gustafson et al [20] reported that $\beta$ galactosidase and TP53 gene expression increased in subcutaneous adipose tissue (scAT) of lean and obese participants in relation to fat cell enlargement. Senescent-like features, including increased SA- $\beta$-gal activity, have been detected in visceral adipose tissue of a limited number of diabetic nonobese individuals [18]. In culture experiments, markers of senescence were higher in pre-adipocytes and endothelial cells derived from adipose tissue of obese vs lean participants [21, 22]. Interestingly, obese adipose tissue conditioned media induced a senescent phenotype in endothelial cells, suggesting that obesity promotes a pro-senescent milieu [21].

The present study was designed to address the pathological relevance of adipose tissue senescence in human obesity. To this aim, we developed a method to quantify SA- $\beta$-gal activity in adipose tissue biopsies on a large-scale basis. Adipose tissue SA- $\beta$-gal status was determined in a prospective cohort of 227 obese participants, including individuals with metabolic complications at different stages of severity. As a working hypothesis, we looked for associations between adipose tissue senescence and alteration of metabolic fitness in human obesity.

\section{Methods}

Participants The study includes 227 obese participants prospectively recruited between 2015 and 2018 in the Prospective Bariatric Surgery Cohort of the Nutrition Department at Pitié-Salpêtrière Hospital. They are part of several studies registered on ClinicalTrials.gov (NCT00476658, NCT01655017, NCT01454232). They met standard bariatric surgery recommendations and are monitored according to bariatric surgery guidelines [23]. All patients provided informed consent. Clinical and biological variables were assessed prior to surgery and at 3,6 and 12 months post surgery in a subgroup of 181 study participants. Ninety-three patients had type 2 diabetes, according to ADA criteria [24]. Lipid metabolism-related complications were found in 182 patients exhibiting dyslipidaemia (triacylglycerol $>1.70 \mathrm{mmol} / \mathrm{l}$; and/or HDL cholesterol [HDL-C] $<1.04 \mathrm{mmol} / \mathrm{l}$ for men or $<1.29 \mathrm{mmol} / \mathrm{l}$ for women; and/or receiving hypolipidaemic drugs). The list of medications for study participants is shown in electronic supplementary material (ESM) Table 1. Total body and trunk (abdominal and arms) fat mass were determined by dual-energy $\mathrm{x}$-ray absorptiometry (DEXA) (GE Lunar Prodigy Corporation, Madison, WI, USA) [25]. Venous blood samples collected in the fasting state were used to assess bioclinical markers
$[26,27]$. HOMA-IR was determined using the HOMA Calculator v2.2.2 (www.dtu.ox.ac.uk/homacalculator/ download.php). QUICKI was determined as described in [28]. The study flow chart is shown in ESM Fig. 1.

Adipose tissue biopsies and SA- $\beta$-gal activity Paired omental adipose tissue (omAT) and scAT adipose tissue biopsies were obtained during bariatric surgery. SA- $\beta$-gal activity was measured in fresh adipose tissue biopsies with the Senescence Cells Histochemical Staining Kit (Sigma, St Louis, MO, USA). We standardised the procedure as follows: $100 \mathrm{mg}$ of adipose tissue was incubated overnight at $37^{\circ} \mathrm{C}$ in $700 \mu$ of staining solution containing $\mathrm{X}$-gal. The reaction was stopped with fixation buffer. When applied to human adipose tissue biopsies, this assay produced a blue-green stain, which was quantified on digitally analysed adipose tissue pictures using Image $\mathrm{J}(\mathrm{NIH}$, USA) (ESM Fig. 2). RGB images were converted into CMKY format (https://imagej.net/RGB_to_CMYK) to measure the cyan value of each pixel. SA- $\beta$-gal values were set as the ratio of cyan pixel intensity over the number of pixels in the biopsy area multiplied by 1000 , and reported as arbitrary units (AU). A subset of scAT and omAT biopsies were incubated for $48 \mathrm{~h}$ prior to SA- $\beta$-gal assay, with or without a cocktail of the senolytic drugs, dasatinib $(1 \mu \mathrm{mol} / \mathrm{l})$ and quercetin $(20 \mu \mathrm{mol} / \mathrm{l})$ (Sigma), following a protocol by Xu et al [29].

Histopathology of adipose tissue Adipocyte diameter was measured with Perfect Image (v 7.7, ClaraVision, Verrières le Buisson, France) on scAT needle-aspirated biopsies after collagenase digestion [30]. Macrophages were detected on adipose tissue slides with the pan-macrophage marker CD68 antibody (DakoCytomation, Trappes, France) and counted per 100 adipocytes [31]. Fibrosis score of adipose tissue (FAT score) was determined on picrosirius red labelled adipose tissue sections using a method by Bel Lassen et al [32]. Hydroxyproline concentration, reflecting collagen content, was measured in adipose tissue biopsies using a colorimetric assay (BioVision, Milpitas, CA, USA) [7].

Adipose tissue explants Adipose tissue explants were prepared from scAT biopsies as described previously [33]. Briefly, adipose tissue was minced in endothelial cell basal medium (Promocell, Heidelberg, Germany) containing 1\% FBS to reach a concentration of $0.1 \mathrm{~g} / \mathrm{ml}$. Twenty-four hour conditioned media was analysed for released factors using ELISA (Biotechne, Mineapolis, MN, USA) or Luminex technology (ThermoFisher, Courtaboeuf, France). In some experiments, explants were incubated for $48 \mathrm{~h}$ with or without a senolytic cocktail of dasatinib $(1 \mu \mathrm{mol} / \mathrm{l})$ and quercetin (20 $\mu \mathrm{mol} / \mathrm{l})$ [29].

Cultured human pre-adipocytes Pre-adipocytes were obtained from stromal vascular cells of adipose tissue collected by 
lipoaspiration in non-obese female participants [34]. To assess the effect of macrophage-derived factors, differentiated blood monocytes were incubated with either $100 \mathrm{ng} / \mathrm{ml}$ lipopolysaccharide (from Escherichia coli 0127:B8) or dexamethasone $(100 \mathrm{nmol} / \mathrm{l})$, to obtain proinflammatory (M1-) and antiinflammatory (M2-) conditioned media (CM), respectively [34]. Pre-adipocytes were cultured for $72 \mathrm{~h}$ in standard medium (control) or with M1- or M2-CM (1/4 vol./vol.). When indicated, a senescence inhibitor roscovitine $(20 \mu \mathrm{mol} / \mathrm{l})$ [35] or a senolytic cocktail of dasatinib $(1 \mu \mathrm{mol} / \mathrm{l})$ and quercetin (20 $\mu \mathrm{mol} / \mathrm{l})$ [29] was added concomitantly with M1-CM. SA- $\beta$-gal activity was determined using the Senescence Cells Histochemical Staining Kit (Sigma), according to the manufacturer's recommendations. The number of blue cells was quantified and expressed as per cent of total cell count per field.

Gene expression analysis Total RNA was extracted from adipose tissue biopsies or cultured pre-adipocytes using the RNeasy Mini Kit (Qiagen, Hilden, Germany). cDNAs were synthesised with M-MLV reverse transcriptase (Promega, Fitchburg, WI, USA). Exiqon primers were used for quantitative real-time PCR using the 7300 real-time PCR system (Applied Biosystems, Foster City, CA, USA). A list of primers used is shown in ESM Table 2. The QuantiGene 2.0 Plex Assay kit (ThermoFisher) was used to quantify some transcripts as indicated. Plates were analysed in the Luminex 200 system (Luminex, Austin, TX, USA) and gene expression was calculated using the xPonent software (v 3.1, Luminex).

PBMC telomere length Peripheral blood mononuclear cells (PBMCs) were isolated from fresh blood samples. Briefly, following plasma removal, blood cells were centrifuged $(10 \mathrm{~min}$ at $1200 \mathrm{~g}$ ) in SepMate PBMC isolation tubes containing Ficoll (STEMCELL Technologies, Grenoble, France). Genomic DNA was extracted from PBMCs with the QIAamp DNA Kit (Qiagen). Telomere length was assessed by real-time quantitative PCR according to [36] and reported as the ratio of telomere copy number over $36 B 4$ (also known as $R P L P O)$ gene (AU).

Statistical analyses Since SA- $\beta$-gal values were not normally distributed, we categorised this variable in tertiles. Statistical tests for comparison between tertiles included Student's $t$ test, Wilcoxon test, ANOVA or linear $p_{\text {trend }}$ for continuous data and $\chi^{2}$ test for categorical data. Correlations were assessed by Spearman's test. To confirm associations between scAT SA- $\beta$-gal and bioclinical characteristics, we used multivariable linear regression allowing adjustments for sex and diabetes status and estimation of their effect size. We (1) assessed the robustness against deviations from normality of these models, (2) $\log _{10}$ transformed non-normal variables when required and (3) evaluated plots of residuals against normal quantiles (QQ-plot). We explored the explained variance of each bioclinical variable in the total variance of $\operatorname{scAT}$ SA- $\beta$ gal by calculating $\eta^{2}$ in generalised linear models [37]. Relations between scAT SA- $\beta$-gal at inclusion and changes in clinical variables over time after bariatric surgery were tested by building linear mixed-effects (LME) models with participants' identification as a random variable [38]. All LME models were fit by maximising the restricted log-likelihood of their estimated coefficients and were adjusted for sex, age, diabetes status and type of surgery (sleeve gastrectomy or gastric bypass). The $p$ value of LME referred to the interaction term between time $(0,3,6$ or 12 months post surgery) and tertiles of scAT SA- $\beta$-gal (categorical variables). Estimates of LME were expressed as adjusted means and 95\% CI. Statistical analyses were performed by using R software (version 2.10.1, http://www.r-project.org) and the SAS system (version 9.0.1 SAS, Cary, NC).

\section{Results}

SA- $\beta$-gal activity predominates in scAT biopsies To explore SA- $\beta$-gal activity, we used a well-established cytochemical assay that we optimised and standardised for human adipose tissue biopsies. This assay generated highly variable blue staining among individuals and fat depots (Fig. 1a). Using an in-house quantification method (ESM Fig. 2), we found that SA- $\beta$-gal staining values were sevenfold lower in omAT than in scAT (Fig. 1b). More than half (52\%) of the omAT biopsies were negative for SA- $\beta$-gal vs $13 \%$ of the scAT samples. In paired biopsies, omAT and scAT SA- $\beta$ gal levels were positively correlated (Fig. 1c). When adipose tissue biopsies were treated with senolytic drugs, SA- $\beta$-gal staining and quantification were markedly reduced in scAT and omAT samples (Fig. 1d).

For following analyses, scAT biopsies were partitioned in tertiles according to Low (0-20 AU), Medium (21-99 AU) or High (100-322 AU) SA- $\beta$-gal activity. scAT SA- $\beta$-gal levels were similar in men and women in the Low and Medium tertiles, but higher in women in the High tertile (Fig. 1e). BMI and age of the study participants were equally distributed among scAT SA- $\beta$-gal tertiles regardless of sex (Fig. 1f,g). To substantiate the lack of association of scAT senescence with chronological ageing, we measured PBMC telomere length, an established marker of organismal ageing, in 61 participants separated in two age groups (50-70 years, $n=30 ; 18-49$ years, $n=31$ ). Reduced telomere length was found in older individuals $(0.649 \pm 0.02 \mathrm{AU})$ compared with younger individuals $(0.772 \pm 0.02 \mathrm{AU}, p<0.01)$, while scAT $\mathrm{SA}-\beta$-gal was similar $(69 \pm 14$ vs $65 \pm 13$ AU, NS). Thus, although a systemic marker of ageing readily identified older people, their scAT senescence status was not aggravated compared with young individuals. 
Fig. 1 SA- $\beta$-gal in adipose tissue biopsies in relation with fat depot, sex, age and BMI. (a)

Representative pictures of paired scAT and omAT biopsies used for quantification of SA- $\beta$-gal staining. Paired biopsies were visually classified in three groups according to the intensity of blue colour in scAT samples. (b) Quantification of SA- $\beta$-gal (AU) in scAT and omAT biopsies in 227 obese participants. (c) Correlation between scAT and omAT SA- $\beta$-gal activity; $r$ and $p$ values were obtained by Spearman test. (d) SA- $\beta$-gal activity in scAT and omAT incubated for $48 \mathrm{~h}$ with a senolytic drug cocktail (D+Q) prior to SA- $\beta$ gal activity assay. (e) Quantification of scAT SA- $\beta$-gal in participants classified by sex and SA- $\beta$-gal tertile. (f, g) Distribution of BMI (f) and age (g) of participants classified by sex and SA- $\beta$-gal tertile. (b, $\mathbf{d}-$ g) Individual data and mean (line) are shown. $*_{p}<0.05, * * p<0.01$ by Student's $t$ test. Tertiles of scAT SA- $\beta$-gal are defined as Low: 0-20 AU; Medium: 21-99 AU; High: 100-322 AU. D, dasatinib; Q, quercetin a
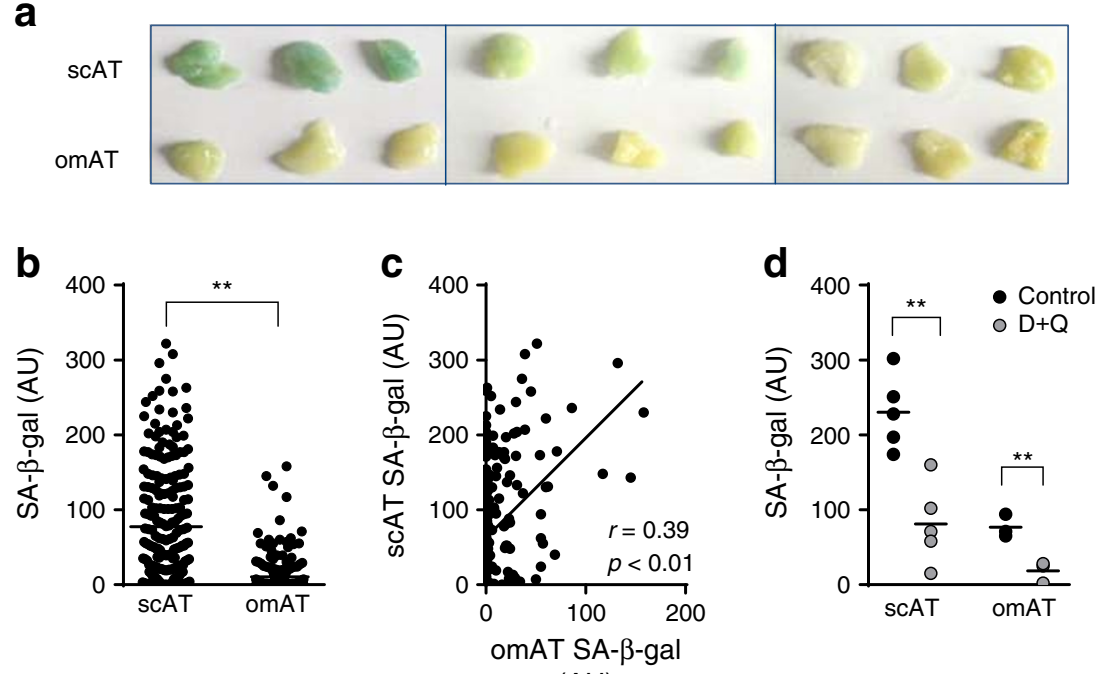

$(\mathrm{AU})$

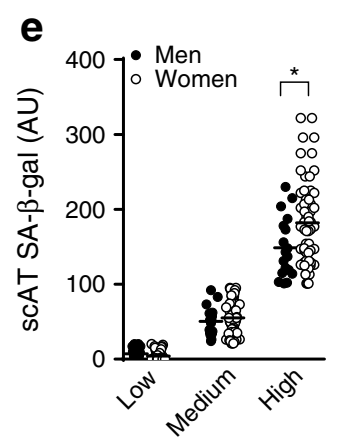

f
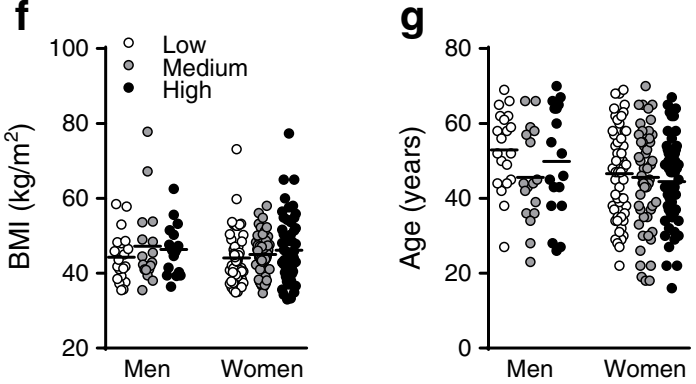

scAT gene and secretory profiles are altered in relation to SA$\beta$-gal We next performed transcription and secretion profiling in scAT biopsies with distinct SA- $\beta$-gal levels. Only a few genes were modified in relation to increasing SA- $\beta$-gal, including SPP1 (which encodes osteopontin), LIPA (lipase A, lysosomal acid type) and $L E P$ (leptin). SPP1 was the most upregulated gene in the High tertile (Fig. 2a). We found no significant change in gene expression of SASP factors (PAII and IGFBP3) or ADIPOQ (which encodes adiponectin). In scAT biopsies with high SA- $\beta$-gal, SPP1 and LIPA upregulation occurred mostly in the stromal vascular cell fraction (SVF), while $L E P$ was overexpressed specifically in adipocytes (Fig. 2b). Although senescence can be induced by oxidative stress, we found no evidence for change in the expression of several antioxidant genes with increasing SA- $\beta$-gal in scAT biopsies (ESM Fig. 3a). Furthermore, scAT expressed higher levels of antioxidant genes than omAT (ESM Fig. 3b), suggesting disconnection of adipose tissue senescent status with the degree of oxidative stress based on this gene expression evaluation. Expression of several other genes was not significantly changed irrespective of SA- $\beta$-gal tertile (ESM Table 3). Specifically, lipogenic genes were not differentially expressed according to SA- $\beta$-gal status. In line with this, an equal partition of adipocyte diameters across tertiles (ESM Fig. 4a) indicates no relationship of adipocyte size with SA- $\beta$-gal in this population. Similarly, we did not detect significant change in expression of classical gene markers of senescence, i.e. P21 (also known as CDKN1A), TP53 and $R B 1$. Finally, stable expression of the profibrotic factor $T G F \beta 1$ (also known as TGFB1) or the collagen isoform COL3A1 suggested no link between SA- $\beta$-gal levels and scAT fibrosis in people with severe obesity (ESM Table 3). Two sets of observations support this assumption. First, hydroxyproline concentrations in scAT were not significantly correlated with SA- $\beta$-gal (ESM Fig. $4 b$ ). Second, SA- $\beta$-gal was not significantly altered in biopsies with FAT scores of increasing severity (ESM Fig. 4c).

The release of several factors, including leptin, plasminogen activator inhibitor 1 (PAI1), insulin-like growth factor binding protein 3 (IGFBP3) and C-C motif chemokine ligand 2 (CCL2) increased progressively up to twofold, together with scAT SA- $\beta$-gal, while IL- 6 and adiponectin release remained stable across tertiles (Fig. 2c). We did not find further evidence for SA- $\beta$-gal-related alteration in scAT secreted factors (ESM Table 4). Importantly, senolytic treatment markedly reduced the release of leptin, PAI1, IGFBP3, CCL2 and 


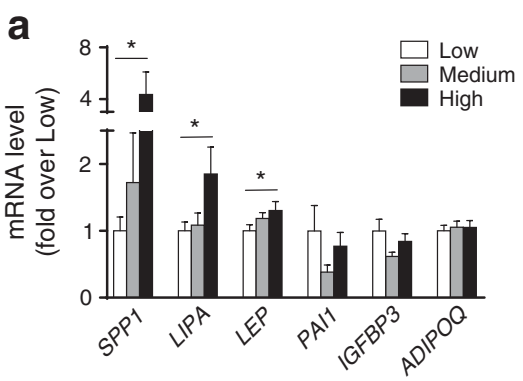

C

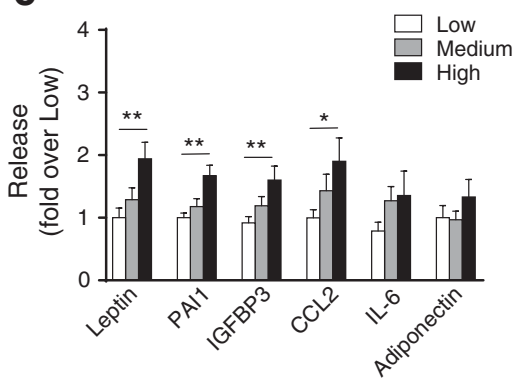

Fig. 2 Gene expression and secretory profiles of scAT biopsies with distinct levels of SA- $\beta$-gal. (a) Senescence-related gene expression in scAT biopsies classified according to tertile of SA- $\beta$-gal. Data are mean \pm SEM of fold change over mean values of Low set to 1 ( $n=11-28$ per tertile). (b) Gene expression of selected factors in SVF and adipocytes from scAT biopsies assigned to the High $(n=12)$ or Low $(n=9)$ SA- $\beta$-gal tertile. Data are mean \pm SEM of relative mRNA levels normalised to $R P L P 0$ mRNA determined by QuantiGene Plex. (c) Release of secreted factors in explants of scAT biopsies classified according to tertile of SA$\beta$-gal. Data are mean \pm SEM of fold change over mean values of Low set

IL-6 specifically in scAT biopsies with High SA- $\beta$-gal (Fig. $2 \mathrm{~d})$. This selective inhibition identifies cells with a senescent phenotype as a source or a trigger of these factors in human adipose tissue.

M1-CM induces a pro-senescent effect in human pre-adipocytes We sought to determine whether proinflammatory macrophages promote senescence. The number of $\mathrm{CD} 68^{+}$ cells in scAT biopsies was not related to SA- $\beta$-gal activity (ESM Fig. 4d). Nevertheless, M1-CM increased the number of SA- $\beta$-gal-positive cells in culture of pre-adipocytes (Fig. $3 a, b)$. This induction did not occur with M2-CM and was reversed by the senescence inhibitory drug roscovitine. Further support for M1-CM pro-senescent effect was provided by upregulation of senescence markers and reversion upon roscovitine or senolytic drug treatments (Fig. 3c-e). M1-CM exhibited a potent proinflammatory effect, as expected, demonstrated by a marked stimulation of CCL 2 and IL- 6 gene expression and release (Fig. 3f,g). Neither senescence- nor inflammation-related factors were significantly changed in response to M2-CM (ESM Fig. 5). Notably, while roscovitine reduced the inflammatory effect of M1-CM, senolytic drugs failed to reverse CCL2 and IL-6 induction (Fig. 3f,g).
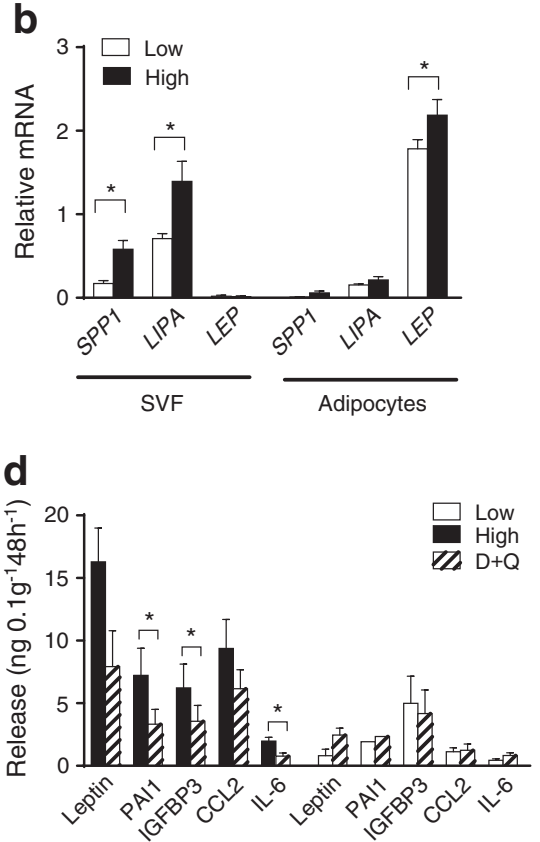

to 1 ( $n=11-28$ per tertile). (d) Secretory profile of explants of scAT biopsies selected in the High $(n=5)$ or Low $(n=5)$ SA- $\beta$-gal tertile. Explants were incubated for $48 \mathrm{~h}$ without or with a senolytic cocktail $(\mathrm{D}+\mathrm{Q})$, as indicated. Data are shown as mean \pm SEM of the amounts released by $0.1 \mathrm{~g}$ of adipose tissue over $48 \mathrm{~h}$. (a, c) $p$ values were obtained by linear $p_{\text {trend }}$ test. (b, d) $p$ values were obtained by unpaired (b) or paired (d) Student's $t$ tests; $* p<0.05 ; * * p<0.01$. Tertiles of scAT SA- $\beta$ gal are defined as Low: 0-20 AU; Medium: 21-99 AU; High: 100-322 AU. D, dasatinib; Q, quercetin

SCAT SA- $\beta$-gal associates with trunk fat mass and insulin resistance markers In our population of severely obese participants, SA- $\beta$-gal was positively associated with serum leptin and markers of insulin resistance, including increased fasting insulin levels and HOMA-IR and reduced QUICKI (Table 1) in both men and women. In women, additional relationships support a link between scAT SA- $\beta$-gal and poor glycaemic status, including elevated fasting glucose levels and $\mathrm{HbA}_{1 \mathrm{c}}$ and low adiponectin. Moreover, women with senescent scAT displayed high trunk fat mass.

Multivariable linear regression and adjustments for sex and type 2 diabetes status confirmed that scAT SA- $\beta$-gal was significantly associated with large trunk fat mass, serum leptin and markers of insulin resistance (Fig. 4a). The effect size of these associations showed that seven bioclinical variables were the best to explain scAT SA- $\beta$-gal variance (Fig. $4 \mathrm{~b}$ ). By contrast, age, BMI, fasting glucose and $\mathrm{HbA}_{1 \mathrm{c}}$ did not significantly contribute to scAT SA- $\beta$-gal variations.

ScAT SA- $\beta$-gal does not impair improvement of metabolic status following bariatric surgery The concordant data found at baseline (i.e. before bariatric surgery) revealed a deleterious relationship between high scAT SA- $\beta$-gal and insulin 
Fig. 3 Effect of macrophage secreted factors on senescence and inflammatory markers in human primary pre-adipocytes. (a) Representative pictures of preadipocytes cultured for $72 \mathrm{~h}$ in the absence (Control) or presence of blood-derived macrophage conditioned media (M1-CM and M2-CM) without or with addition of a senescence inhibitory drug roscovitine as indicated. (b) Percentage of cells staining positive for SA- $\beta$-gal (blue cells) in the same culture conditions as in (a). Means and individual data are shown. $* p<0.05, * * p<0.01$ by Student's $t$ test. (c) Expression of genes related to cell cycle in preadipocytes cultured for $72 \mathrm{~h}$ in the absence (control) or presence of M1-CM (M1). When indicated a senolytic cocktail (D+Q) or roscovitine was added concomitantly with M1-CM. Gene expression was determined by QuantiGene Plex. (d-g) Gene expression $(\mathbf{d}, \mathbf{f})$ and release $(\mathbf{e}, \mathbf{g})$ of senescence and inflammatory markers in the same culture conditions as in (c). (c-g) Means and individual data of fold change over control mean value (straight line) set to 1 are shown. $* p<0.05$ by paired Student's $t$ test. D, dasatinib; Q, quercetin; Rosco, roscovitine

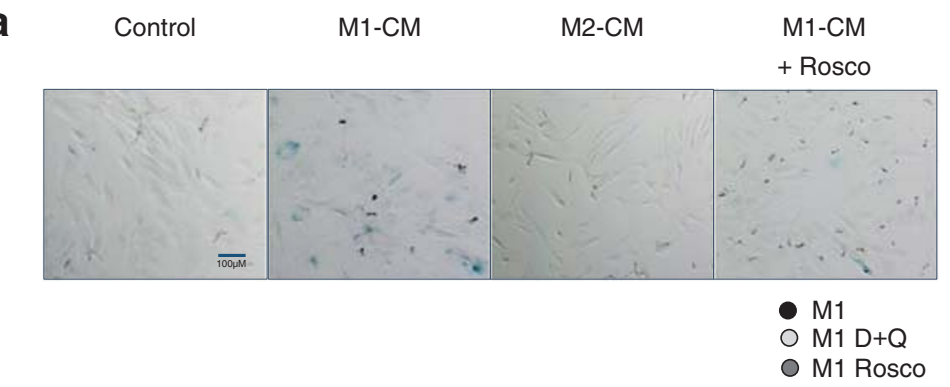

b

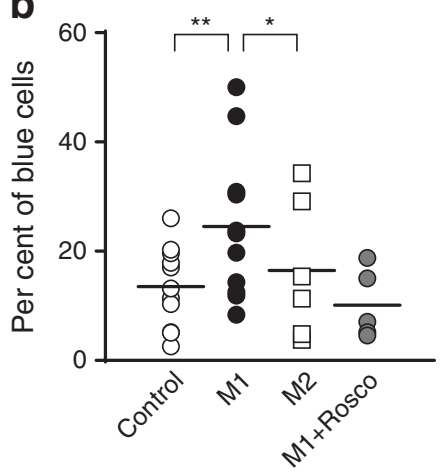

d

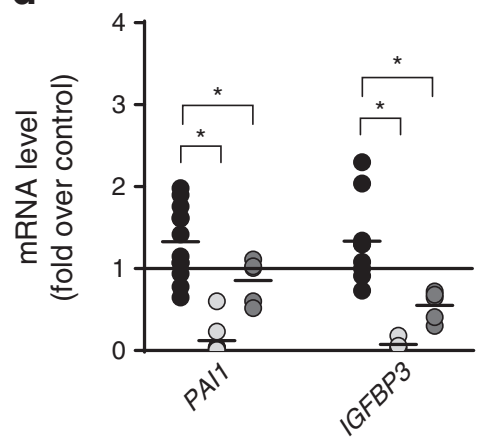

f

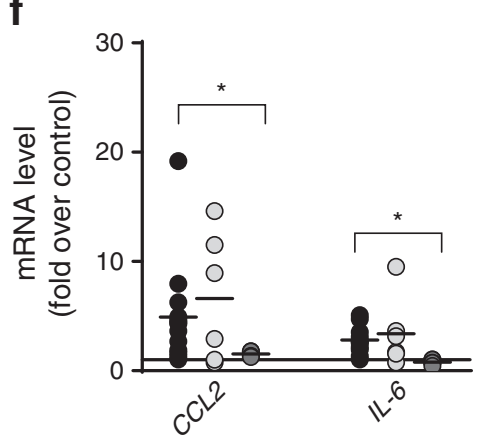

C

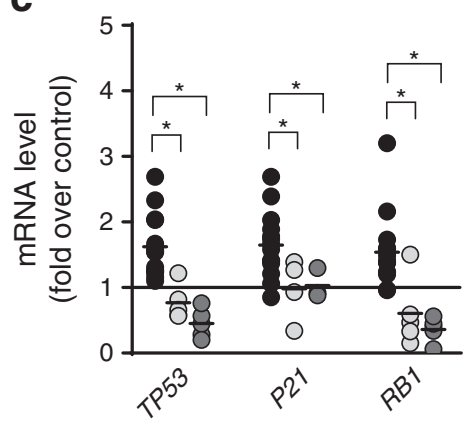

e

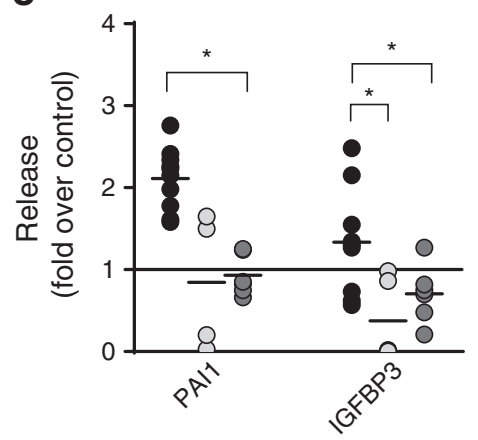

g

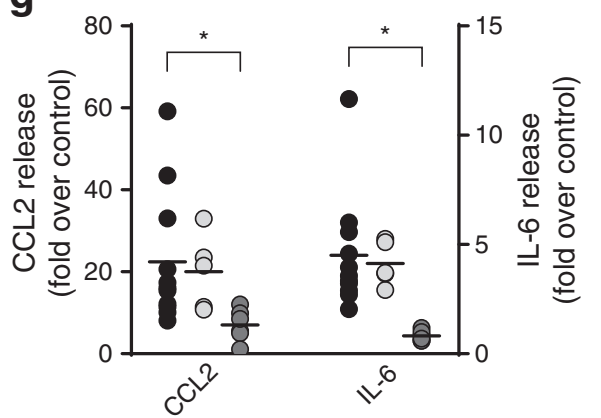

resistance phenotypes. In line with this, the number of participants with type 2 diabetes was twice as high in the High scAT SA- $\beta$-gal tertile than in the other groups at inclusion (Fig. 4c). Importantly, all diabetic patients received similar drug treatment (ESM Table 5), indicating that this unequal partition of type 2 diabetic patients was not accounted for by distinct medication. As a well-established beneficial consequence of bariatric surgery, the number of diabetic patients decreased progressively over 1 year (Fig. 4c). Notably, both total remission or improvement of diabetes confirmed by reduced use of glucose-lowering treatments occurred irrespective of patients' initial assignment to SA- $\beta$-gal tertile (ESM Table 6,7). At inclusion, increased numbers of patients with dyslipidaemia or low HDL-C were classified in the High and Medium SA- $\beta$ gal tertiles (Fig. 4d,e). After surgery, the number of affected patients decreased regularly in each group, reaching similar 


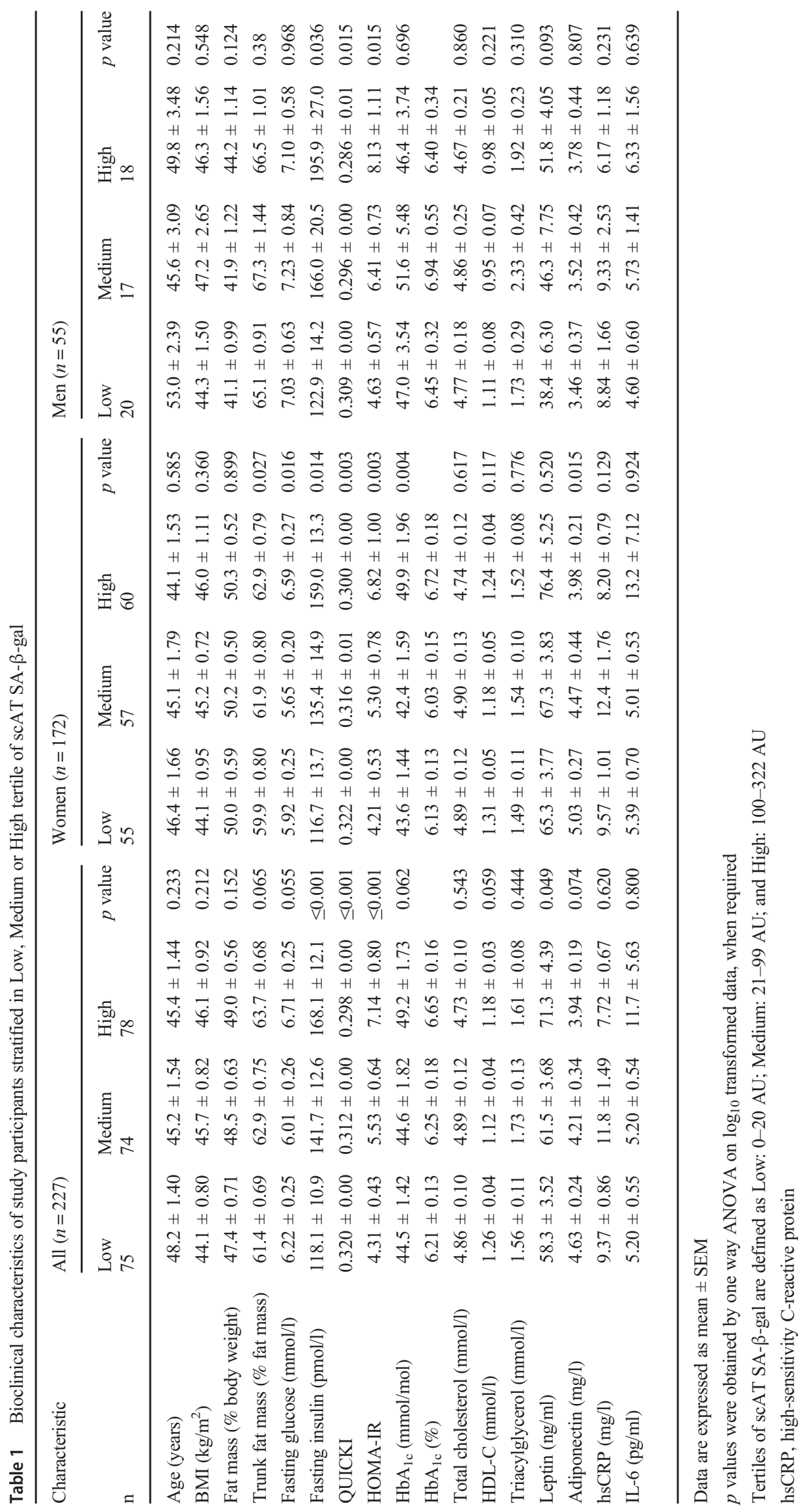


Fig. 4 Relations between scAT SA- $\beta$-gal and bioclinical variables in obese individuals at surgery and during post-surgery follow-up. (a) Heat map of multivariable linear regressions between bioclinical variables and scAT SA- $\beta$-gal, not adjusted or with adjustments as indicated ( $n=227)$. $* p<0.05, * * p<0.01$. (b) Effect size of standardised discriminant variables explaining percentages of total scAT SA- $\beta$ gal variance $(n=227)$.

Significance refers to a global generalised linear model including all indicated variables. (c-e) Number of participants with obesity-linked metabolic complications expressed as a percentage within each tertile of scAT SA- $\beta$-gal at inclusion (time 0 ). Patients remained assigned to their initial SA- $\beta$-gal tertile for post-surgery follow-up at 3, 6 and 12 months $(n=181)$. Comparison between tertiles at each time point was performed by $\chi^{2}$-test. ${ }^{*} p<0.05, * * p<0.01$. (f-g) Mixed models of post-surgery evolution of selected variables in patients assigned to tertiles of scAT SA- $\beta$ gal at inclusion $(n=181)$. Data were normalised over baseline (time 0 ). The interaction term between time and scAT SA- $\beta$-gal tertile at baseline was statistically significant $(p<0.05$ for each graph). (c-h) Tertiles of scAT SA- $\beta$-gal defined as Low: $0-20$ AU; Medium: 21-99 AU; High: 100-322 AU. T2D, type 2 diabetes a
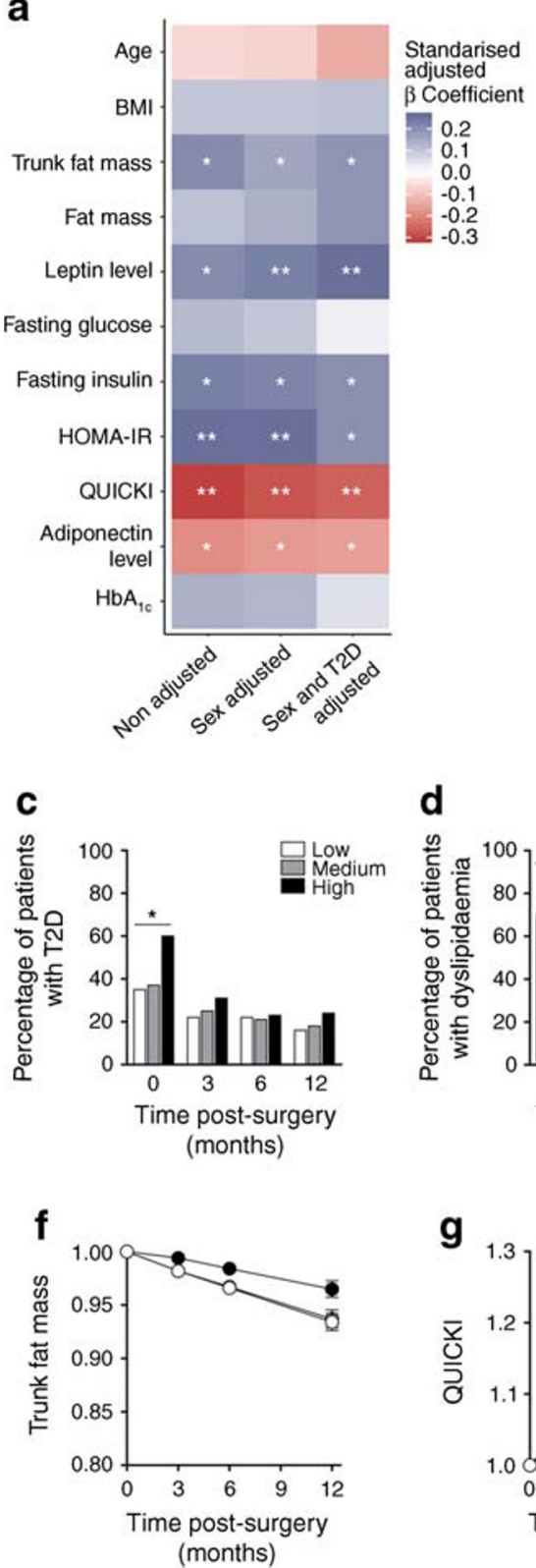

b

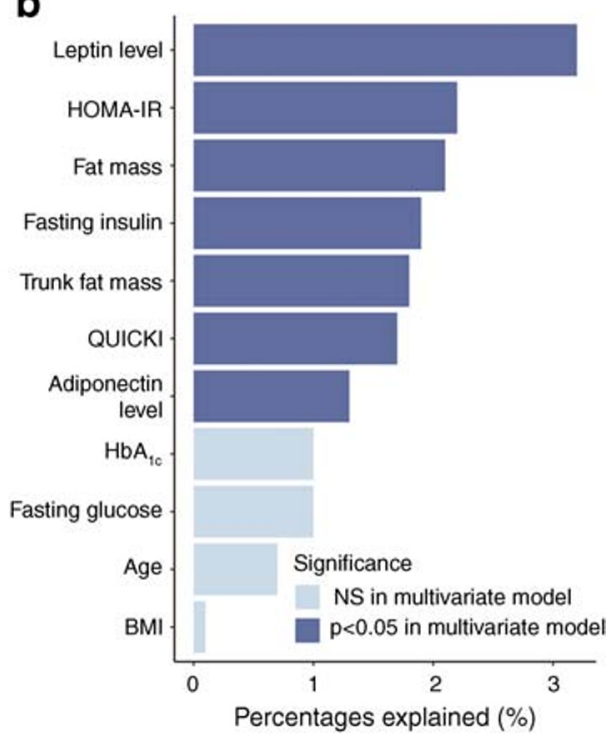

d

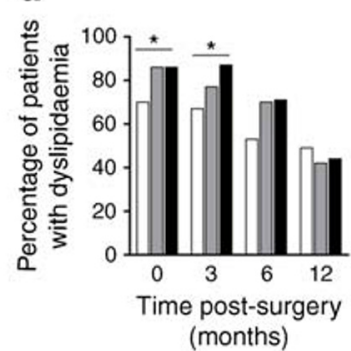

g

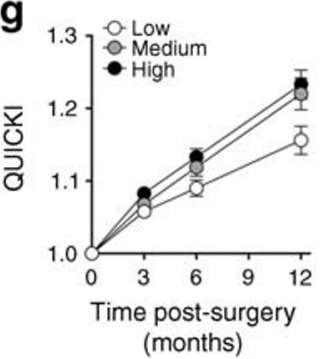

e

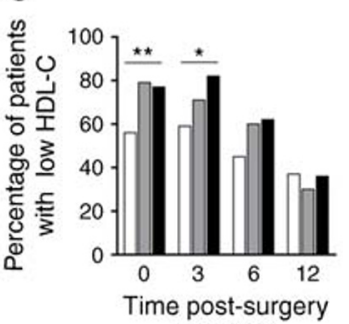

(months)

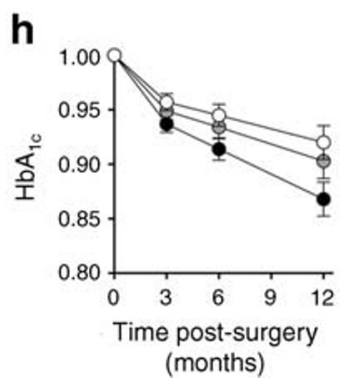

values at 6 and 12 months post surgery. Thus, metabolic anomalies were more prevalent in patients with high scAT senescence status at baseline, but improved with bariatric surgery irrespective of the initial level of SA- $\beta$-gal.

After adjustment for sex, diabetes status and type of surgery, a few bioclinical variables showed significantly distinct profiles of post-surgery evolution according to scAT SA- $\beta$-gal at inclusion (Table 2). When normalised over baseline, trunk fat mass, QUICKI and $\mathrm{HbA}_{1 \mathrm{c}}$ showed a distinct time course over 1 year post surgery. Participants classified in the High SA- $\beta$-gal tertile were characterised by lower trunk fat mass loss but enhanced QUICKI and reduced $\mathrm{HbA}_{1 \mathrm{c}}$ compared with other tertiles (Fig. 4f-h).

\section{Discussion}

This study is, to our knowledge, the first addressing the potential contribution of adipose tissue senescence to metabolic complications in human severe obesity. We show that adipose tissue from a large group of people displays highly variable degrees of senescence reflected by a large range of SA- $\beta$-gal levels. In this specific population with severe obesity, senescent scAT represents a hallmark of poor glycaemic status. Importantly and surprisingly, scAT SA- $\beta$-gal was unrelated to chronological ageing, indicating that obesity associates with premature senescence in this tissue. However, a high degree of senescence in scAT did not preclude improvement of metabolic markers after bariatric surgery. 


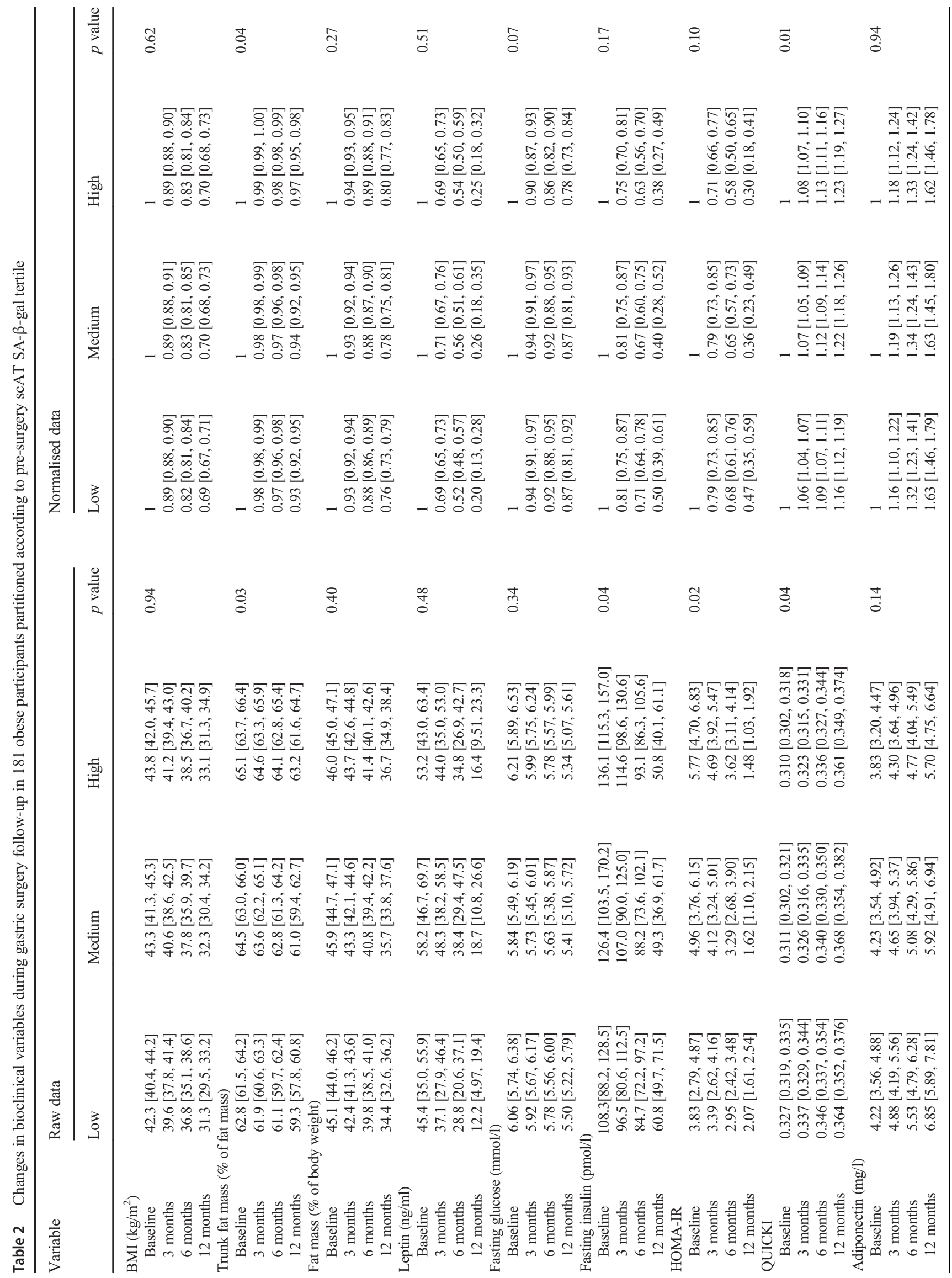




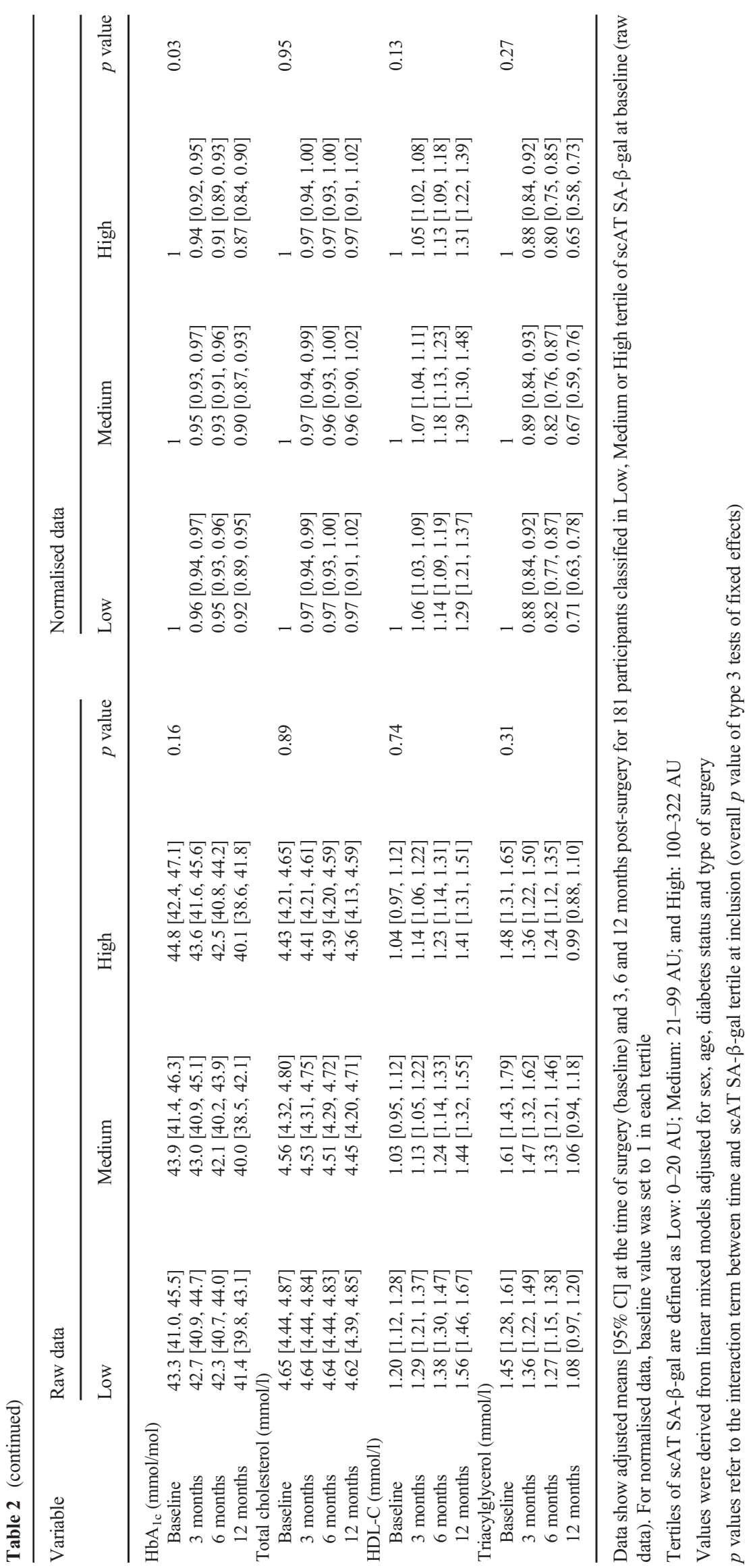


Given the established contribution of visceral fat to metabolic injuries [39], we expected high senescence status in omAT. Contrary to this hypothesis, SA- $\beta$-gal was either not detectable or found in low range values in omAT biopsies. Currently, we have no explanation for this previously unidentified fat depot-specific difference in human obesity. Disconnection between scAT SA- $\beta$-gal and chronological ageing suggests implication of age-independent factors, remaining to be identified.

A set of data gives support to SA- $\beta$-gal being a relevant marker of human adipose tissue senescence status. First, SA- $\beta$-gal staining in adipose tissue biopsies significantly decreased upon senolytic treatment. Second, gene expression and release of several established SASP components increased with SA- $\beta$-gal in scAT and were downregulated by senolytics selectively in biopsies expressing high levels of SA- $\beta$-gal activity. Third, M1 macrophage-derived factors increased SA- $\beta$-gal along with other senescence markers in cultured human pre-adipocytes. This induction was readily abolished by senolytic drugs and by roscovitine. By contrast, the potent proinflammatory effect of M1-CM previously established $[34,40]$ and confirmed here, was resistant to the inhibitory effect of senolytic drugs. This indicates that M1 macrophages trigger inflammation and senescence through distinct pathways, with a prominent activation of inflammatory signalling. Notably, roscovitine reduced M1-induced inflammation, in line with the capacity of this drug to repress NF-kB inflammatory pathways [41]. The mechanisms by which the drug reduces SA- $\beta$-gal activity and other senescence markers in human pre-adipocytes remain to be determined.

Performing ex vivo and in vitro exploration on human samples, we defined senescence-associated and inflammatory factors produced by senescent adipose tissue. This includes CCL2, IL-6, PAI1, IGFBP3 and leptin, which could be considered SASP factors in human scAT. One of the genes most upregulated in senescent scAT was SSP1, encoding osteopontin. Recently, adipose tissue-derived osteopontin has been implicated in age-related cardiac fibrosis and dysfunction in mice [42]. Further studies are needed to establish whether osteopontin is a component of human scAT SASP. As such, this protein might contribute, with other SASP deleterious factors, to obesity-linked cardiometabolic complications.

We tested the hypothesis that senescence contributes to adipose tissue pathological remodelling in human obesity. We found no evidence for a link between lipogenic gene expression or adipocyte size and SA- $\beta$-gal, suggesting that senescence does not influence triacylglycerol storage in obese scAT. In a distinct population comprising lean and moderately obese individuals, $\beta$-galactosidase gene expression in scAT was shown to increase with adipocyte size [20]. This relationship might reflect expansion of the lysosomal compartment with cell enlargement, not specifically related to senescence, since $\beta$-galactosidase gene expression does not fully account for the senescent phenotype detected by SA- $\beta$-gal assay [14]. Macrophage accumulation is another well recognised deleterious cellular alteration that was not linked with scAT senescence status, although this does not preclude association with M1-activated macrophages. Finally, we found no relationship between scAT SA- $\beta$-gal activity and FAT score stages, which readily detected increasing degree of fibrosis severity in our current population with severe obesity, similar to our previously explored cohort [32]. In sum, our current observations do not support a major contribution of senescence to aggravate local scAT deterioration at the severe and chronic stages of obesity.

The large spectrum of SA- $\beta$-gal levels found in the present study suggests highly variable senescence status of scAT. In obese women, SA- $\beta$-gal levels were associated with increased trunk fat mass. Concordant observations also highlight a relationship between scAT SA- $\beta$-gal and insulin resistance phenotypes. Ex vivo analyses showed that senescent scAT produces molecules implicated in the alteration of glucose homeostasis, such as IL-6 [43] or IGFBP3 [44], which could contribute to these deleterious phenotypes. Although a causal relationship is virtually impossible to establish in humans, mouse studies support a pathological role for adipose tissue senescent cells. Indeed, deletion or overexpression of TP53 in obese mice caused improved or aggravated insulin resistance, respectively [18]. Other studies showed that a decline in adipose tissue senescence markers in response to exercise or through senolytic treatment was associated with amelioration of glycaemic status in diet-induced obese mice $[19,45]$.

Clinical investigation of the study participants revealed that metabolic anomalies, including type 2 diabetes and dyslipidaemia, were more frequent in obese participants with senescent scAT. Nevertheless, well-established beneficial effects of bariatric surgery on insulin resistance phenotypes occurred independently of scAT senescence status before surgery. We cannot exclude the possibility that surgeryinduced amelioration of scAT senescence status, together with a decreased proinflammatory milieu, contributed to improve recovery in participants with high SA- $\beta$-gal at inclusion. Postsurgery scAT SA- $\beta$-gal was not measured in the present study, given that surgical biopsies were not available.

Cellular senescence promotes deterioration of a broad range of physiological functions in aged mice that can be reversed or delayed through elimination of senescent cells $[29,46]$. Specifically, several obesity-related pathologies might be driven by senescent cell accumulation in various organs. This includes non-alcoholic fatty liver disease (NAFLD) and anxiety disorders, which have been attributed to the senescence status of hepatocytes and glial cells, respectively, in obese mice [47, 48]. Notably, hepatocyte senescence has also been reported in chronic liver disease in humans [49]. 
Whether senescent scAT-derived factors contribute to these alterations needs to be explored deeper in human obesity.

The strength of our human study relies on the demonstration that SA- $\beta$-gal staining in scAT is positively linked to altered glycaemic status. We believe that this brings to light a new feature of adipose tissue dysfunctional state driving metabolic diseases in humans. Nevertheless, we acknowledge some limitations. First, the SA- $\beta$-gal assay provides a global evaluation of senescence in adipose tissue. Further studies are needed to unequivocally identify adipose tissue senescent cell types by combining staining of markers of senescence and cellular identity, as proposed by Biran et al [50]. Second, the pathological relevance of senescence in human adipose tissue was explored exclusively in participants with severe to morbid obesity. Although this allowed us to link adipose tissue senescence to altered glycaemic status in this severe phenotype, this deleterious relationship remains to be explored in cohorts of lean, overweight or less obese individuals. Finally, the surprisingly low levels of SA- $\beta$-gal in omAT ruled out further investigation. We cannot exclude that other senescence markers would be more appropriate to quantify low degrees of senescence in this fat depot.

In conclusion, adipose tissue is a site of pathological cellular remodelling, which eventually leads to disruption of metabolic homeostasis in obesity. Our data revealed that scAT senescence is another hallmark of these alterations in severe obesity, with highly variable degrees of senescence linked to altered glucose metabolism and deleterious truncal fat distribution. Given the promising results of senescent cell elimination in mice, senolytic treatment could alleviate senescent cell accumulation in scAT and, in turn, reduce obesity-induced metabolic complications.

Acknowledgements We thank V. Lemoine (Institute of Cardiometabolism and Nutrition, ICAN) and F. Marchelli (Assistance Publique-hôpitaux de Paris) for patient recruitment and data management, as well as P. Bel Lassen (Assistance Publique-hôpitaux de Paris) and J. Debédat (Sorbonne University) for useful discussions.

Data availability All data are available on request from the corresponding author.

Funding This work was supported by the RHU (Réseau HospitaloUniversitaire)-CARMMA (CARdiac \& skeletal Muscle alteration in relation to Metabolic diseases and Aging: role of adipose tissue) grant (National Agency of Research, ANR-15-RHUS-0003). Additional funding was obtained from the National Agency of Research (ANRCaptor project and ANR-10-IAHU-05 IHU-ICAN), the FORCE network (as part of F-Crin, French Clinical Research Infrastructure), the Fondation pour la Recherche Médicale (FRM-DEQ20120323701) and the clinical research contract (Fibrota-NCT01655017). Clinical investigation was performed at the Human Nutrition Research Center (Centre de Recherche en Nutrition Humaine Île-de-France).

Authors' relationships and activities The authors declare that there are no relationships or activities that might bias, or be perceived to bias, their work.
Contribution statement $\mathrm{KC}$ and GD designed the study as part of RHU-CARMMA. ChR conducted ex vivo experiments, obtained and analysed data and prepared figures. CiR contributed to pre-adipocyte culture experiments and critically revised data. SoA performed and interpreted statistical analyses. MA and GM set up SA- $\beta$-gal quantification in human adipose tissue biopsies, and analysed and interpreted the data. CP, JA-W, LG and $\mathrm{KC}$ were in charge of patient recruitment and performed deep clinical phenotyping. LG and J-CB provided human adipose tissue biopsies and lipoaspirate and contributed to clinical data acquisition. YZ set up and performed the measure of PBMC telomere length. SeA and FM analysed and critically revised inflammatory profiling. KC and MG-M analysed and interpreted data, drafted the article and revised the main manuscript text. All authors reviewed the manuscript text and figures and approved the final version. $\mathrm{KC}$ is the guarantor of this study.

\section{References}

1. Sun K, Kusminski CM, Scherer PE (2011) Adipose tissue remodeling and obesity. J Clin Invest 121(6):2094-2101. https://doi.org/ 10.1172/JCI45887

2. Osborn O, Olefsky JM (2012) The cellular and signaling networks linking the immune system and metabolism in disease. Nat Med 18(3):363-374. https://doi.org/10.1038/nm.2627

3. Mathis D (2013) Immunological goings-on in visceral adipose tissue. Cell Metab 17(6):851-859. https://doi.org/10.1016/j.cmet. 2013.05.008

4. Caër C, Rouault C, Le Roy T et al (2017) Immune cell-derived cytokines contribute to obesity-related inflammation, fibrogenesis and metabolic deregulation in human adipose tissue. Sci Rep 7(1): 3000. https://doi.org/10.1038/s41598-017-02660-w

5. Dalmas E, Venteclef N, Caer C et al (2014) T cell-derived IL-22 amplifies IL-1 $\beta$-driven inflammation in human adipose tissue: relevance to obesity and type 2 diabetes. Diabetes 63(6):1966-1977. https://doi.org/10.2337/db13-1511

6. Deng T, Lyon CJ, Minze LJ et al (2013) Class II major histocompatibility complex plays an essential role in obesity-induced adipose inflammation. Cell Metab 17(3):411-422. https://doi.org/ 10.1016/j.cmet.2013.02.009

7. Marcelin G, Ferreira A, Liu Y et al (2017) A PDGFR $\alpha$-mediated switch toward CD $9^{\text {high }}$ adipocyte progenitors controls obesityinduced adipose tissue fibrosis. Cell Metab 25(3):673-685. https://doi.org/10.1016/j.cmet.2017.01.010

8. Sun Y, Coppé J-P, Lam EW-F (2018) Cellular senescence: the sought or the unwanted? Trends Mol Med 24(10):871-885. https://doi.org/10.1016/j.molmed.2018.08.002

9. Coppé J-P, Desprez P-Y, Krtolica A, Campisi J (2010) The senescence-associated secretory phenotype: the dark side of tumor suppression. Annu Rev Pathol 5(1):99-118. https://doi.org/10. 1146/annurev-pathol-121808-102144

10. Gorgoulis V, Adams PD, Alimonti A et al (2019) Cellular senescence: defining a path forward. Cell 179(4):813-827. https://doi. org/10.1016/j.cell.2019.10.005

11. Özcan S, Alessio N, Acar MB et al (2016) Unbiased analysis of senescence associated secretory phenotype (SASP) to identify common components following different genotoxic stresses. Aging 8(7):1316-1329. https://doi.org/10.18632/aging.100971

12. Dimri GP, Lee X, Basile G et al (1995) A biomarker that identifies senescent human cells in culture and in aging skin in vivo. Proc Natl Acad Sci U S A 92(20):9363-9367. https://doi.org/10.1073/pnas. 92.20 .9363 
13. Kurz DJ, Decary S, Hong Y, Erusalimsky JD (2000) Senescenceassociated $\beta$-galactosidase reflects an increase in lysosomal mass during replicative ageing of human endothelial cells. J Cell Sci 113(Pt 20):3613-3622

14. Lee BY, Han JA, Im JS et al (2006) Senescence-associated $\beta$ galactosidase is lysosomal $\beta$-galactosidase. Aging Cell 5(2):187195. https://doi.org/10.1111/j.1474-9726.2006.00199.x

15. Thoppil H, Riabowol K (2019) Senolytics: a translational bridge between cellular senescence and organismal aging. Front Cell Dev Biol 7:367. https://doi.org/10.3389/fcell.2019.00367

16. Zhu Y, Tchkonia T, Pirtskhalava T et al (2015) The Achilles' heel of senescent cells: from transcriptome to senolytic drugs. Aging Cell 14(4):644-658. https://doi.org/10.1111/acel.12344

17. Hickson LJ, Langhi Prata LGP, Bobart SA et al (2019) Senolytics decrease senescent cells in humans: preliminary report from a clinical trial of Dasatinib plus Quercetin in individuals with diabetic kidney disease. EBioMedicine 47:446-456. https://doi.org/10. 1016/j.ebiom.2019.08.069

18. Minamino T, Orimo M, Shimizu I et al (2009) A crucial role for adipose tissue TP53 in the regulation of insulin resistance. Nat Med 15(9):1082-1087. https://doi.org/10.1038/nm.2014

19. Palmer AK, Xu M, Zhu Y et al (2019) Targeting senescent cells alleviates obesity-induced metabolic dysfunction. Aging Cell 18(3):e12950. https://doi.org/10.1111/acel.12950

20. Gustafson B, Nerstedt A, Smith U (2019) Reduced subcutaneous adipogenesis in human hypertrophic obesity is linked to senescent precursor cells. Nat Commun 10(1):2757. https://doi.org/10.1038/ s41467-019-10688-x

21. Villaret A, Galitzky J, Decaunes P et al (2010) Adipose tissue endothelial cells from obese human subjects: differences among depots in angiogenic, metabolic, and inflammatory gene expression and cellular senescence. Diabetes 59(11):2755-2763. https://oi. org $/ 10.2337 / \mathrm{db} 10-0398$

22. Tchkonia T, Morbeck DE, Von Zglinicki T et al (2010) Fat tissue, aging, and cellular senescence. Aging Cell 9(5):667-684. https:// doi.org/10.1111/j.1474-9726.2010.00608.x

23. Fried M, Yumuk V, Oppert JM et al (2014) Interdisciplinary European guidelines on metabolic and bariatric surgery. Obes Surg 24(1):42-55. https://doi.org/10.1007/s11695-013-1079-8

24. American Diabetes Association (2015) (2) Classification and diagnosis of diabetes. Diabetes Care 38(Suppl):S8-S16. https://doi.org/ $10.2337 / \mathrm{dc} 15-\mathrm{S} 005$

25. Coupaye M, Bouillot J-L, Poitou C, Schutz Y, Basdevant A, Oppert J-M (2007) Is lean body mass decreased after obesity treatment by adjustable gastric banding? Obes Surg 17(4):427-433. https://doi. org/10.1007/s11695-007-9072-8

26. Aron-Wisnewsky J, Sokolovska N, Liu Y et al (2017) The advanced-DiaRem score improves prediction of diabetes remission 1 year post-Roux-en-Y gastric bypass. Diabetologia 60(10):18921902. https://doi.org/10.1007/s00125-017-4371-7

27. Debédat J, Sokolovska N, Coupaye M et al (2018) Long-term relapse of type 2 diabetes after Roux-en-Y gastric bypass: prediction and clinical relevance. Diabetes Care 41(10):2086-2095. https://doi.org/10.2337/dc18-0567

28. Katz A, Nambi SS, Mather K et al (2000) Quantitative insulin sensitivity check index: a simple, accurate method for assessing insulin sensitivity in humans. J Clin Endocrinol Metab 85(7): 2402-2410. https://doi.org/10.1210/jcem.85.7.6661

29. Xu M, Pirtskhalava T, Farr JN et al (2018) Senolytics improve physical function and increase lifespan in old age. Nat Med 24(8): 1246-1256. https://doi.org/10.1038/s41591-018-0092-9

30. Divoux A, Tordjman J, Lacasa D et al (2010) Fibrosis in human adipose tissue: composition, distribution, and link with lipid metabolism and fat mass loss. Diabetes 59(11):2817-2825. https://doi. org/10.2337/db10-0585
31. Dalmas E, Kahn J-F, Giral P et al (2013) Intima-media thickness in severe obesity: links with BMI and metabolic status but not with systemic or adipose tissue inflammation. Diabetes Care 36(11): 3793-3802. https://doi.org/10.2337/dc13-0256

32. Bel Lassen P, Charlotte F, Liu Y et al (2017) The FAT Score, a Fibrosis Score of Adipose Tissue: predicting weight-loss outcome after gastric bypass. J Clin Endocrinol Metab 102(7):2443-2453. https://doi.org/10.1210/jc.2017-00138

33. Rouault C, Pellegrinelli V, Schilch R et al (2013) Roles of chemokine ligand-2 (CXCL2) and neutrophils in influencing endothelial cell function and inflammation of human adipose tissue. Endocrinology 154(3):1069-1079. https://doi.org/10.1210/en. 2012-1415

34. Lacasa D, Taleb S, Keophiphath M, Miranville A, Clement K (2007) Macrophage-secreted factors impair human adipogenesis: involvement of proinflammatory state in preadipocytes. Endocrinology 148(2):868-877. https://doi.org/10.1210/en.20060687

35. Alexander K, Yang H-S, Hinds PW (2004) Cellular senescence requires CDK5 repression of Rac1 activity. Mol Cell Biol 24(7): 2808-2819. https://doi.org/10.1128/MCB.24.7.2808-2819.2004

36. Mouraret N, Houssaïni A, Abid S et al (2015) Role for telomerase in pulmonary hypertension. Circulation 131(8):742-755. https:// doi.org/10.1161/CIRCULATIONAHA.114.013258

37. Richardson JTE (2011) Eta squared and partial eta squared as measures of effect size in educational research. Educ Res Rev 6(2):135-147. https://doi.org/10.1016/j.edurev.2010.12.001

38. Finucane MM, Samet JH, Horton NJ (2007) Translational methods in biostatistics: linear mixed effect regression models of alcohol consumption and HIV disease progression over time. Epidemiol Perspect Innov EPI 4(1):8. https://doi.org/10.1186/1742-5573-4-8

39. Tchernof A, Després J-P (2013) Pathophysiology of human visceral obesity: an update. Physiol Rev 93(1):359-404. https://doi.org/10. 1152/physrev.00033.2011

40. Keophiphath M, Achard V, Henegar C, Rouault C, Clément K, Lacasa D (2009) Macrophage-secreted factors promote a profibrotic phenotype in human preadipocytes. Mol Endocrinol Baltim Md 23(1):11-24. https://doi.org/10.1210/me.2008-0183

41. Dey A, Wong ET, Cheok CF, Tergaonkar V, Lane DP (2008) RRoscovitine simultaneously targets both the TP53 and NF-KB pathways and causes potentiation of apoptosis: implications in cancer therapy. Cell Death Differ 15(2):263-273. https://doi.org/10.1038/ sj.cdd. 4402257

42. Sawaki D, Czibik G, Pini M et al (2018) Visceral adipose tissue drives cardiac aging through modulation of fibroblast senescence by osteopontin production. Circulation. 138(8):809-822. https:// doi.org/10.1161/CIRCULATIONAHA.117.031358

43. Bastard J-P, Maachi M, Van Nhieu JT et al (2002) Adipose tissue IL-6 content correlates with resistance to insulin activation of glucose uptake both in vivo and in vitro. J Clin Endocrinol Metab 87(5):2084-2089. https://doi.org/10.1210/jcem.87.5.8450

44. Chan SSY, Twigg SM, Firth SM, Baxter RC (2005) Insulin-like growth factor binding protein-3 leads to insulin resistance in adipocytes. J Clin Endocrinol Metab 90(12):6588-6595. https://doi.org/ 10.1210/jc.2005-0595

45. Schafer MJ, White TA, Evans G et al (2016) Exercise prevents dietinduced cellular senescence in adipose tissue. Diabetes 65(6):16061615. https://doi.org/10.2337/db15-0291

46. Baker DJ, Wijshake T, Tchkonia T et al (2011) Clearance of p16 ${ }^{\text {Ink4a }}$-positive senescent cells delays ageing-associated disorders. Nature 479(7372):232-236. https://doi.org/10.1038/ nature 10600

47. Ogrodnik M, Miwa S, Tchkonia T et al (2017) Cellular senescence drives age-dependent hepatic steatosis. Nat Commun 8(1):15691. https://doi.org/10.1038/ncomms15691 
48. Ogrodnik M, Zhu Y, Langhi LGP et al (2019) Obesity-induced cellular senescence drives anxiety and impairs neurogenesis. Cell Metab 29(5):1061-1077.e8. https://doi.org/10.1016/j.cmet.2018. 12.008

49. Aravinthan A, Challis B, Shannon N, Hoare M, Heaney J, Alexander GJM (2015) Selective insulin resistance in hepatocyte senescence. Exp Cell Res 331(1):38-45. https://doi.org/10.1016/j. yexcr.2014.09.025
50. Biran A, Zada L, Abou Karam P et al (2017) Quantitative identification of senescent cells in aging and disease. Aging Cell 16(4): 661-671. https://doi.org/10.1111/acel.12592

Publisher's note Springer Nature remains neutral with regard to jurisdictional claims in published maps and institutional affiliations.

\section{Affiliations}

\section{Christine Rouault ${ }^{1} \cdot$ Geneviève Marcelin $^{1} \cdot$ Solia Adriouch ${ }^{1} \cdot$ Cindy Rose $^{1} \cdot$ Laurent Genser $^{1,2} \cdot$ Marc Ambrosini $^{1}$. Jean-Christophe Bichet ${ }^{3}$ - Yanyan Zhang ${ }^{4}$ • Florian Marquet ${ }^{1}$. Judith Aron-Wisnewsky ${ }^{1,5} \cdot$ Christine Poitou $^{1,5}$. Sébastien André ${ }^{1} \cdot$ Geneviève Dérumeaux $^{4,6} \cdot$ Michèle Guerre-Millo ${ }^{1} \cdot$ Karine Clément $^{1,5}$}

1 Sorbonne Université, Inserm, Nutrition and Obesities: Systemic Approaches (Nutriomics), Paris, France

2 Assistance Publique Hôpitaux de Paris, Visceral Surgery Department, Pitié-Salpêtrière Hospital, Paris, France

3 Assistance Publique Hôpitaux de Paris, Service de Chirurgie et Cancérologie Gynécologique et Mammaire, Pitié-Salpêtrière Hospital, Paris, France
4 Inserm U955, Université Paris-Est Créteil (UPEC), Créteil, France

5 Assistance Publique Hôpitaux de Paris, Nutrition Department, CRNH Ile de France, Pitié-Salpêtrière Hospital, Paris, France

6 Assistance Publique Hôpitaux de Paris, Department of Cardiology, Henri Mondor Hospital, DHU-ATVB, Créteil, France 